\title{
Index and strength properties of clay-gravel mixtures
}

1 Benjamin S. Kyambadde MSC Division of Civil Engineering, University of Brighton, UK
2. Kevin J. L. Stone PhD, CEng, MICE

Division of Civil Engineering, University of Brighton, UK
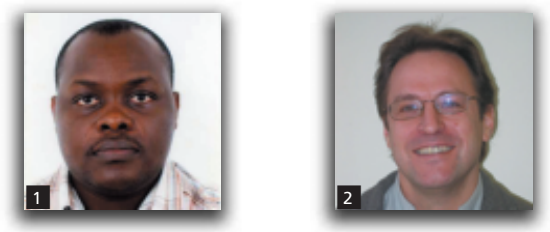

This paper reports the results of fall-cone tests and quasi-static cone penetration tests undertaken on mixtures of fine gravel and highly plastic clay. The influence of the gravel on the plasticity of the mixture is quantified through the derivation of liquid and plastic limits obtained by direct testing of the mixture. The plastic limit used in this study is defined as the moisture content corresponding to a hundredfold increase in the liquid limit undrained strength, and is denoted by $\mathrm{PL}_{100}$. Liquid limits were determined from conventional fall-cone tests. The range of plasticity of the mixture is defined through the plasticity index, derived from the fall-cone liquid limit and the $\mathrm{PL}_{100}$ index. The study demonstrates that the plasticity of mixtures of fine- and coarse-grained soil can be quantified without the requirement to remove the coarser fraction. The influence of the coarse fraction on both the undrained shear strength and the index properties was observed to be significant for gravel volume fractions greater than about $50 \%$. This gravel volume fraction is associated with the maximum void ratio of the gravel, which suggests that interaction between the gravel particles at high gravel contents results in a frictional contribution to the mixture behaviour.

\section{Notation}

C clay content

d penetration depth

$F \quad$ static penetration force; weight of fall cone

$G \quad$ gravel content

$h \quad$ static penetration depth

K cone factor

LL liquid limit

M mass

$N_{\gamma} \quad$ bearing capacity factor

PI plasticity index (LL - PL)

$\mathrm{PI}_{100}$ additional plasticity index (LL $\left.-\mathrm{PL}_{100}\right)$

PL plastic limit

$\mathrm{PL}_{100} \quad$ additional plastic limit

$s_{\mathrm{u}} \quad$ undrained shear strength

V volume

w moisture content

\section{Introduction}

This paper presents the results of fall-cone tests and quasi-static cone penetration tests performed on mixtures of fine gravel (particle size $2.0-3.35 \mathrm{~mm}$ ) and highly plastic clay from the Reading Beds Formation. The study was undertaken to assess the influence of the fine gravel fraction on the index properties and undrained shear strength, particularly at the lower end of the plasticity range, that is, in the vicinity of the plastic limit (PL).

The importance of the coarser fraction for the plasticity of soils was illustrated by Dumbleton and West (1966) in their study of kaolinite and montmorillonite mixed with crushed and uncrushed glass beads and quartz sand. The study was, however, limited to the soil fraction finer than $0.425 \mathrm{~mm}$.

More recent studies on the influence of fine gravel on the mechanical behaviour of kaolin clay reported by Kumar (1996), Kumar and Muir Wood (1999) and Muir Wood and Kumar (2000) have shown that the liquid limit (LL) of the mixture is controlled entirely by the clay matrix for clay contents above about $35 \%$, with a significant influence of the gravel on the mixture behaviour being observed at a granular volume fraction above about $0 \cdot 45$. From data reported by Sivapullaiah and Sridharan (1985), it can be established that for mixtures of fine sand and bentonite the liquid limit is entirely dependent on the clay matrix for clay fractions as low as about $20 \%$. This variation of the range over which the mixture behaviour is entirely dependent on the clay matrix may be attributed to the quantity and mineralogy of the fine fraction, which controls the specific surface area of the soil. The presence of a coarser fraction in the mixed soil reduces the specific surface area, thereby reducing the plasticity of the soil. 
The influence of the fine gravel on the plastic limit of kaolin clay was not determined in the studies reported by Kumar (1996), Kumar and Muir Wood (1999) and Muir Wood and Kumar (2000), owing to the limitations of the BS 'thread rolling' plastic limit test outlined in BS 1377-2 (BSI, 1990). However, Stone and Phan (1995) developed an approach that utilises a quasi-static cone penetration to measure an alternative plastic limit of a cohesive soil, denoted $\mathrm{PL}_{100}$. This parameter, based on the proposition of Wood and Wroth (1978) of a hundredfold correlation of LL and PL undrained shear strengths, represents the moisture content associated with an undrained strength 100 times that at the fall-cone liquid limit (LL).

Analyses of the cone penetration test presented by Houlsby (1982) showed that a cone that would be in equilibrium at a penetration $h$, when slowly pushed, would penetrate to a depth $h / \sqrt{3}$ if allowed to fall under its own weight (starting at rest, with the cone tip touching the soil surface). It therefore follows that if strain-rate effects are ignored, then the $\mathrm{PL}_{100}$ index, determined from a quasi-static penetration test, corresponds to the moisture content associated with an $8 \mathrm{~kg}(78.5 \mathrm{~N})$ penetration load at a penetration depth of $11.55 \mathrm{~mm}(20 / \sqrt{3})$.

Kumar and Muir Wood (1999) contended that nothing in the BS fall-cone LL test procedure prohibits the fall-cone penetration of mixtures of clay and fine gravel. It is assumed that the same applies to the quasi-static cone penetration tests reported herein, where a similar $30^{\circ}$ conical indenter is used.

\section{Mass-volume relationships}

Various mass-volume relationships were applied in the analysis of the fall-cone and quasi-static penetration tests. Referring to the unit soil model presented in Figure 1, the following relationships between the mass $M$, volume $V$, and gravel $G$ and clay contents $C$ for the mixtures (subscripted ' $M$ ') can be derived (see for example, Kumar and Muir Wood, 1999; Muir Wood and Kumar, 2000).

Clay content of mixture

$$
\text { 1. } C_{\mathrm{M}}=\frac{M_{\mathrm{C}}}{M_{\mathrm{C}}+M_{\mathrm{G}}}
$$

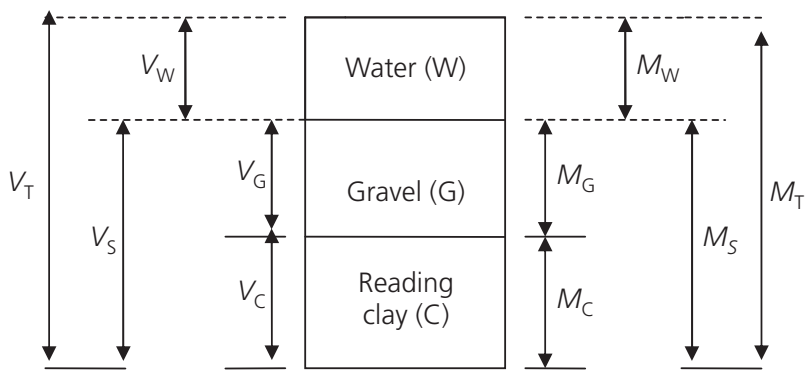

Figure 1. Saturated soil mixture model
Gravel content of mixture

2. $G_{\mathrm{M}}=1-C_{\mathrm{M}}$

Note that the clay content of the mixture $\left(C_{\mathrm{M}}\right)$ refers to the fraction finer than $0.425 \mathrm{~mm}$.

Since full saturation enables the nature of cohesive soils to be easily represented by moisture content (Atkinson, 1993), the variation of index properties of the mixtures with their constituent clay and gravel phases can be correlated, thereby establishing the influence of each phase on the mixture response. The following moisture content relationships can be defined.

Moisture content of mixture

3. $w_{\mathrm{M}}=\frac{M_{\mathrm{W}}}{M_{\mathrm{C}}+M_{\mathrm{G}}}$

where $M_{\mathrm{W}}$ is the mass of water.

Moisture content of clay phase alone (or clay phase moisture content)

4. $w_{\mathrm{C}}=\frac{M_{\mathrm{W}}}{M_{\mathrm{C}}}$

which, from Equations 1, 3 and 4, can also be expressed as

5. $w_{\mathrm{C}}=\frac{w_{\mathrm{M}}}{C_{\mathrm{M}}}$

For any mixture, a plasticity index of the mixture $\left(\mathrm{PI}_{100 \mathrm{M}}\right)$ can be defined as

6. $\mathrm{PI}_{100 \mathrm{M}}=\mathrm{LL}_{\mathrm{M}}-\mathrm{PL}_{100 \mathrm{M}}$

where $\mathrm{LL}_{\mathrm{M}}$ is the liquid limit of the mixture as derived from fallcone tests, and $\mathrm{PL}_{100 \mathrm{M}}$ is the moisture content of the mixture associated with an undrained shear strength 100 times that at the liquid limit $\left(\mathrm{LL}_{\mathrm{M}}\right)$.

The consistency limits for the clay-gravel mixtures can be normalised with respect to the clay content $\left(C_{\mathrm{M}}\right)$ and the consistency limits of the clay content (namely $\mathrm{LL}_{\mathrm{C}}, \mathrm{PL}_{100 \mathrm{C}}$ and $\mathrm{PI}_{100 \mathrm{C}}$ ) as follows.

7. $\mathrm{LL}_{\mathrm{NC}}=\frac{\mathrm{LL}_{\mathrm{M}}}{C_{\mathrm{M}} \mathrm{LL}_{\mathrm{C}}}$ 
8. $\mathrm{PL}_{100 \mathrm{NC}}=\frac{\mathrm{PL}_{100 \mathrm{M}}}{C_{\mathrm{M}} \mathrm{PL}_{100 \mathrm{C}}}$

9. $\quad \mathrm{PI}_{100 \mathrm{NC}}=\frac{\mathrm{PI}_{100 \mathrm{M}}}{C_{\mathrm{M}} \mathrm{PI}_{100 \mathrm{C}}}$

These relationships are used to illustrate the influence of the clay content on the index properties of the mixtures.

\section{Materials and test methods}

\subsection{Materials}

The clay used in this study was sourced from Clapham, in southeast England. The clay is generally referred to as Reading clay, and is a member of the Lambeth Group of soils. It is a highly plastic clay, and comprised about $95 \%$ fines, of which about 34 $40 \%$ were smaller than $2 \mu \mathrm{m}$ (Kyambadde, 2003). It consists mostly of illite, with some kaolinite and traces of smectite. The index properties of the clay were determined in accordance with BS 1377-2 (BSI, 1990), and are summarised in Table 1.

Fine uniformly graded gravel of particle size range $2 \cdot 0-3.35 \mathrm{~mm}$ was selected for the study. The gravel was composed of subrounded to sub-angular quartz particles (about 95\%) with a small fraction of flint and occasional calcareous grains.

\subsection{Preparation of clay-gravel mixtures}

Mixtures of Reading clay and fine gravel were prepared on the basis of the component dry weights, making due allowance for hygroscopic moisture contents. Dry Reading clay, from which particles coarser than $0.425 \mathrm{~mm}$ had been removed, was handmixed with deionised water using a spatula for about $15 \mathrm{~min}$. The required gravel fraction was then added, and mixing continued for another $45 \mathrm{~min}$, with water being added to achieve a suitable moisture content. Thereafter the mixture was placed in an airtight container and left to stand for about 2 weeks prior to testing. Throughout the sample preparation process, care was taken to avoid crushing of the gravel particles.

\begin{tabular}{lc}
\hline Property & Value \\
\hline Specific gravity & $2 \cdot 79$ \\
Liquid limit, LL: \% & 57 \\
Plastic limit, PL: \% & 20 \\
Plasticity index, Pl: \% & 37 \\
Clay fraction (<0.002 mm): \% & $34-40$ \\
Fines (<0.06 mm): \% & 95 \\
Table 1. Index properties of Reading clay &
\end{tabular}

\subsection{Test procedures \\ 3.3.1 Fall-cone test}

The fall-cone test procedure was essentially as described in BS 1377-2 (BSI, 1990), except that the soil fraction coarser than $0.425 \mathrm{~mm}$ was not removed. Also, estimation of the penetration depth for a set of fall-cone drops was modified to account for the presence of the gravel fraction. In the conventional fall-cone test a minimum variation in penetration depth for any two consecutive drops of $0.5 \mathrm{~mm}$ is specified, with a further proviso that for a set of three drops the overall variation shall remain within $1 \mathrm{~mm}$.

For the clay-gravel mixtures an initial set of three fall-cone tests were conducted. If the range of penetration depths was within $1 \mathrm{~mm}$, then no further drops were performed, and the average penetration was recorded. However, if the range of penetrations exceeded $1 \mathrm{~mm}$, a further three drops were performed, and the penetration depth was calculated as the average of the six drops, provided the range did not exceed $3.35 \mathrm{~mm}$ (the maximum fine gravel particle size). Additional drops were performed if required to achieve a set of six within the required penetration range. It was noted that the median penetration depth was very similar to the average penetration depth, and so the use of either approach would result in the same value for the liquid limit of the mixture.

\subsubsection{Quasi-static cone tests}

Quasi-static cone penetration tests were conducted at a penetration rate of $1.0 \mathrm{~mm} / \mathrm{s}$ using a soil mini-penetrometer (SMP), a full description of which can be found in Stone and Kyambadde (2005).

Sample preparation was as described above for the fall-cone tests, except that samples were tested at moisture contents in the vicinity of the plastic limit. The procedure for determining the $\mathrm{PL}_{100}$ has been described in detail elsewhere (e.g. Stone and Kyambadde, 2005, 2007), and is illustrated in the following section.

\section{Results}

\subsection{Undrained shear strength}

Provided no interaction with the gravel particles occurs, it can be assumed that the undrained shear strength of the clay phase controls the penetration of the cone into the mixture (Mitchell and Soga, 2005). Analysis of both the fall-cone test (Hansbo, 1957; Wroth and Wood, 1978) and the static penetration test (Houlsby, 1982) has shown that the undrained shear strength $\left(s_{\mathrm{u}}\right)$ is related to the penetration depth $(d)$ by the simple expression

$$
\text { 10. } s_{\mathrm{u}}=\frac{K F}{d^{2}}
$$

where $F$ represents either the static penetration force or the weight of the fall-cone, and $K$ is the corresponding cone factor for use with the quasi-static or fall-cone test data. 
Koumoto and Houlsby (2001) have shown that the undrained strength exhibited by fine-grained soils in the cone penetration test is dependent on the strain rate. It would therefore be expected that different cone factors should apply for the different penetration rates associated with the fall-cone test and the quasi-static penetration test, and that these factors could incorporate any strain rate effects.

For the fall-cone tests, a cone factor of 0.85 was used. This value was reported by Wood (1985), who compared fall-cone penetration results with undrained strengths measured using a miniature vane shear apparatus. This value reflects a reasonable 'average' value to those reported in the literature (e.g. Brown and Huxley, 1996; Karlsson, 1961; Sharma and Bora, 2003; Sivakumar et al., 2009), and when used with Equation 10 corresponds to an undrained strength at the liquid limit of $1.7 \mathrm{kPa}$.

For the quasi-static penetration tests a cone factor of 0.53 reported by Kyambadde (2010) was used. This factor was obtained by relating the results of quasi-static penetration tests to the undrained strength measured in laboratory vane shear tests using a database in excess of 80 different soils, and is somewhat lower than factors reported from more limited studies (Medhat and Whyte, 1986). It is evident that the use of this cone factor together with a penetration load of $8 \mathrm{~kg}$ and a penetration depth of $11.55 \mathrm{~mm}$ yields a high value of undrained strength at the $\mathrm{PL}_{100}$ of $318 \mathrm{kPa}$.

However, an appropriate quasi-static penetration depth associated with a soil strength 100 times that mobilised in the fall-cone test, and thus at the $\mathrm{PL}_{100}$, would be higher than the theoretical $11.55 \mathrm{~mm}$ if rate effects are considered (e.g. Sivakumar et al., 2009). Recent empirical data reported by Kyambadde (2010) suggest that an appropriate value would be about $17 \mathrm{~mm}$, which corresponds to an undrained strength of about $140 \mathrm{kPa}$ using a quasi-static cone factor of 0.53 . However, for the purposes of this study, any effects of the coarse fraction on the index properties of the Reading clay may be quantified whatever penetration depth is chosen to define $\mathrm{PL}_{100}$, and for consistency with earlier definitions and usage (e.g. Stone and Kyambadde, 2005, 2007; Stone and Phan, 1995) a $\mathrm{PL}_{100}$ value defined at the theoretically derived $11.55 \mathrm{~mm}$ is used.

Equation 10 is used to interpret the fall-cone and quasi-static cone tests to obtain undrained shear strengths. However, at gravel contents greater than about $45 \%$ it was observed that the relationship shown in Equation 10 is no longer valid, and the penetration load was not proportional to the square of the penetration depth. This is illustrated in Figure 2, which shows a plot of the penetration load $F$ against the square of the penetration depth $\left(d^{2}\right)$ for mixtures comprising up to $75 \%$ fine gravel. It is apparent that a linear relationship between $F$ and $d^{2}$, as implied by Equation 10, is evident only for mixtures containing up to about $45 \%$ gravel.

It is assumed that the breakdown in the relationship is the result

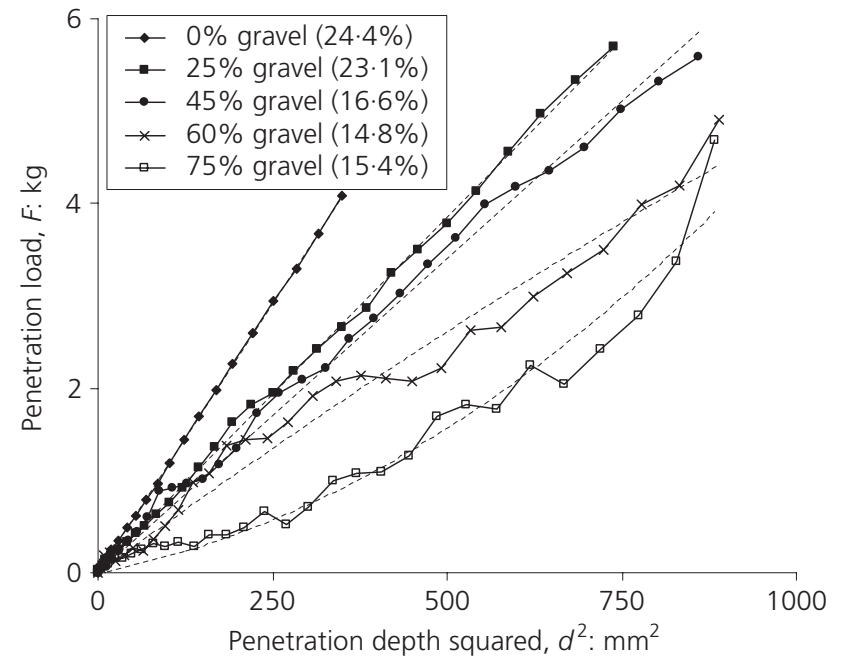

Figure 2. Quasi-static cone penetration curves for clay contents up to $75 \%$ (mixture moisture content in brackets)

of the shear strength of the mixture having a frictional component resulting from the interaction of the gravel particles. Thus Equation 10 should not be applied to mixtures with gravel contents greater than $45 \%$. Consequently, it is not possible to determine the undrained strengths for these mixtures from the tests reported herein.

Figure 3 shows the clay phase moisture content $w_{\mathrm{C}}$, estimated using Equation 5, plotted against the undrained shear strengths derived from the fall-cone and quasi-static cone penetration tests for mixtures with gravel fractions up to $45 \%$ using Equation 10; the data are also presented in Table 2. It is interesting to note that the undrained shear strengths of the mixtures appear to be unaffected by the presence of the gravel, with only a slight effect being observed for the $45 \%$ gravel mixture. It is likely that, at high gravel contents $(>45 \%)$, interaction between the gravel

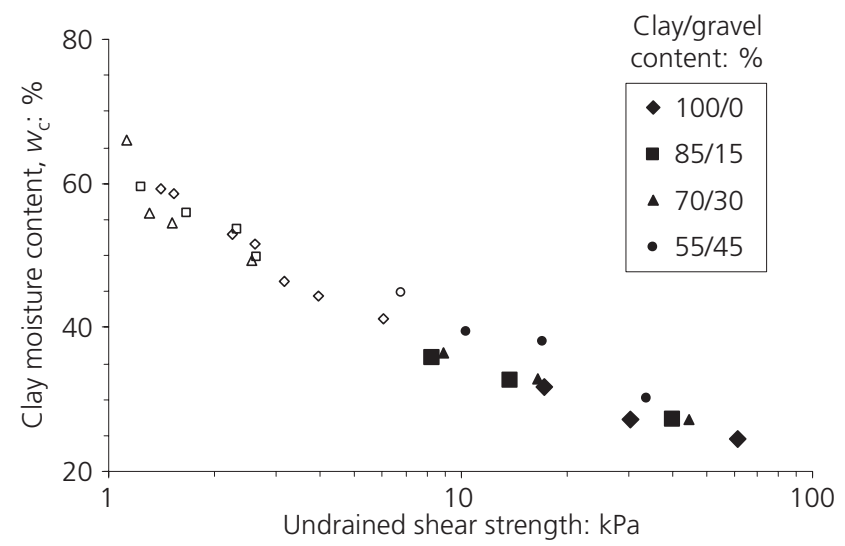

Figure 3. Clay moisture content against undrained shear strength of mixtures; open data points from fall-cone tests 


\begin{tabular}{|c|c|c|c|c|}
\hline $\begin{array}{l}\text { Clay/gravel } \\
\text { content: } \%\end{array}$ & $\begin{array}{l}\text { Mixture moisture } \\
\text { content: \% }\end{array}$ & $\begin{array}{l}\text { Penetration test type and cone } \\
\text { factor, } K\end{array}$ & $\mathrm{~F} / \mathrm{d}^{2}: \mathrm{kg} / \mathrm{mm}^{2}$ & $\begin{array}{l}\text { Undrained shear strength, } \\
\qquad S_{\mathrm{u}}: \mathrm{kPa} \\
\left(=K \times F / d^{2} \times 9810\right]\end{array}$ \\
\hline \multirow[t]{8}{*}{$100 / 0$} & $41 \cdot 2$ & \multirow[t]{5}{*}{ BS fall cone; $K=0.85$} & 0.000712 & $5 \cdot 94$ \\
\hline & $44 \cdot 4$ & & 0.000466 & 3.89 \\
\hline & $46 \cdot 4$ & & 0.000375 & $3 \cdot 13$ \\
\hline & $51 \cdot 5$ & & 0.000309 & $2 \cdot 58$ \\
\hline & $58 \cdot 5$ & & 0.000181 & $1 \cdot 51$ \\
\hline & $24 \cdot 4$ & \multirow[t]{3}{*}{ BS quasi-static cone; $K=0.53$} & 0.011876 & $61 \cdot 75$ \\
\hline & $27 \cdot 2$ & & 0.006155 & $32 \cdot 00$ \\
\hline & $31 \cdot 8$ & & 0.003326 & $17 \cdot 29$ \\
\hline \multirow[t]{7}{*}{$85 / 15$} & $49 \cdot 9$ & \multirow[t]{4}{*}{ BS fall cone; $K=0.85$} & 0.000312 & $2 \cdot 60$ \\
\hline & $53 \cdot 6$ & & 0.000274 & $2 \cdot 28$ \\
\hline & $55 \cdot 9$ & & 0.000198 & $1 \cdot 65$ \\
\hline & $59 \cdot 4$ & & 0.000147 & $1 \cdot 23$ \\
\hline & $27 \cdot 2$ & \multirow[t]{3}{*}{ BS quasi-static cone; $K=0.53$} & 0.007714 & $40 \cdot 11$ \\
\hline & $32 \cdot 7$ & & 0.002643 & $13 \cdot 74$ \\
\hline & $35 \cdot 8$ & & 0.001626 & 8.46 \\
\hline \multirow[t]{7}{*}{$70 / 30$} & $49 \cdot 4$ & \multirow[t]{4}{*}{ BS fall cone; $K=0.85$} & 0.000301 & $2 \cdot 51$ \\
\hline & $54 \cdot 4$ & & 0.000180 & $1 \cdot 50$ \\
\hline & $55 \cdot 9$ & & 0.000155 & $1 \cdot 29$ \\
\hline & $66 \cdot 0$ & & 0.000133 & $1 \cdot 11$ \\
\hline & $27 \cdot 3$ & \multirow[t]{3}{*}{ BS quasi-static cone; $K=0.53$} & 0.008535 & $44 \cdot 38$ \\
\hline & $32 \cdot 9$ & & 0.003062 & $15 \cdot 92$ \\
\hline & $36 \cdot 6$ & & 0.001917 & $9 \cdot 96$ \\
\hline \multirow[t]{7}{*}{$55 / 45$} & $44 \cdot 9$ & \multirow[t]{4}{*}{ BS fall cone; $K=0.85$} & 0.000800 & $6 \cdot 67$ \\
\hline & $52 \cdot 9$ & & 0.000267 & $2 \cdot 23$ \\
\hline & $59 \cdot 3$ & & 0.000167 & $1 \cdot 39$ \\
\hline & $68 \cdot 7$ & & 0.000097 & 0.81 \\
\hline & $30 \cdot 2$ & \multirow[t]{3}{*}{ BS quasi-static cone; $K=0.53$} & 0.006816 & $35 \cdot 43$ \\
\hline & $38 \cdot 0$ & & 0.003196 & $16 \cdot 62$ \\
\hline & $39 \cdot 4$ & & 0.001948 & $10 \cdot 13$ \\
\hline
\end{tabular}

Table 2. Summary of remoulded undrained shear strengths for Reading clay-gravel mixtures from BS fall cone and quasi-static $1 \mathrm{~mm} / \mathrm{s}$ cone penetration tests

particles results in relatively higher shear strengths due to frictional effects.

\subsection{Index properties}

The results of the quasi-static penetration tests are presented in Figures 4(a) to 4(f), showing plots of penetration load against the square of the penetration depth for all the mixtures. From these plots the penetration depth associated with an $8 \mathrm{~kg}$ penetration load is determined, either directly or by extrapolation. For the relationship presented in Equation 10, it is apparent that the data presented in Figures 4(a) and 4(d) are well fitted and extrapolated using a linear regression.

For the high gravel content samples (see Figures 4(e) and 4(f) for the $60 \%$ and $75 \%$ gravel content respectively), it is apparent that Equation 10 no longer applies. However, it seems reasonable to assume that the penetration force is directly associated with the bearing capacity factor $N_{\gamma}$. Therefore, for a frictional material, the penetration force may be expected to be directly proportional to the cube of the penetration depth (i.e. $F \propto d^{3}$ ), and there is some justification in using a parabolic function to extrapolate the data presented in Figures 4(e) and 4(f).

If tests are performed at lower moisture contents, then much less extrapolation would be required. It is suggested that the optimum range of penetration loads for use in a set of quasistatic tests would be between 4 and $8 \mathrm{~kg}$. Although such data would be preferred, it is also recognised that preparing samples at such low moisture contents is difficult and time consuming, and so there remains a requirement to develop test procedures further to optimise sample preparation and data extrapolation. 


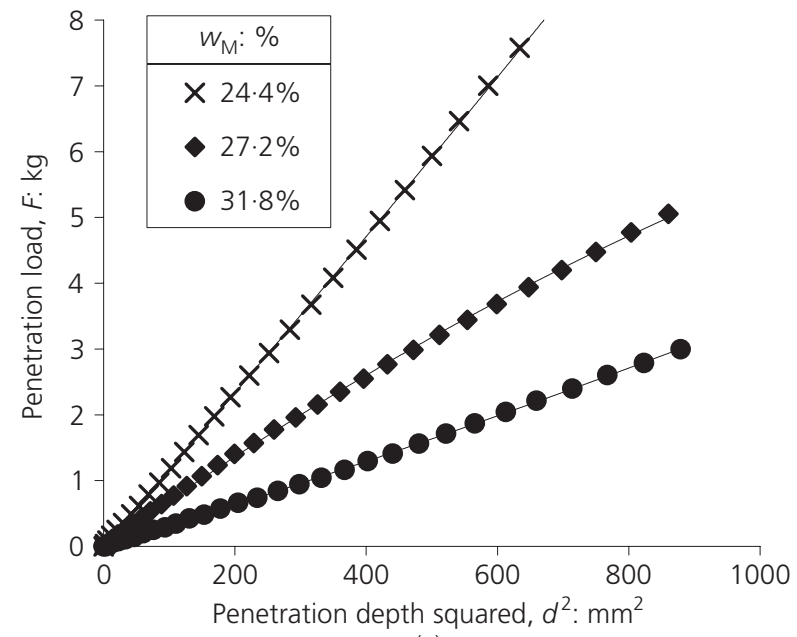

(a)

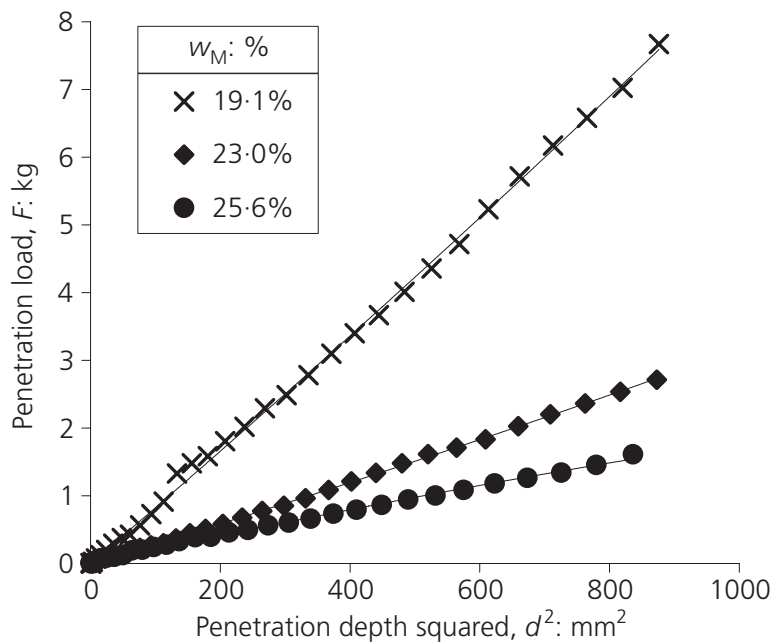

(c)

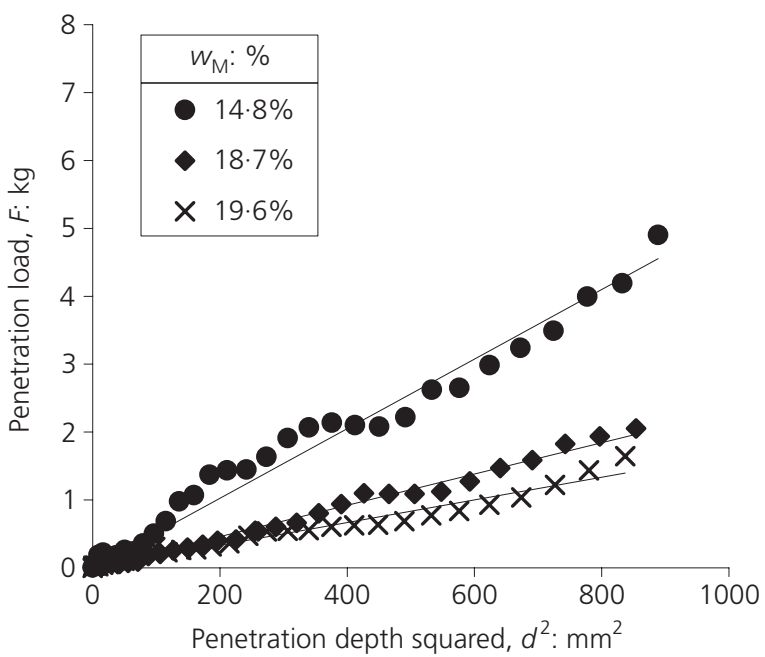

(e)

Figure 4. Quasi-static cone penetration depth against penetration load for clay-gravel mixtures: (a) 100\% clay, $0 \%$ gravel; (b) $85 \%$ clay, $15 \%$ gravel; (c) $70 \%$ clay, $30 \%$ gravel; (d) $55 \%$ clay, $45 \%$ gravel; (e) $40 \%$ clay, $60 \%$ gravel; (f) $25 \%$ clay, $75 \%$ gravel

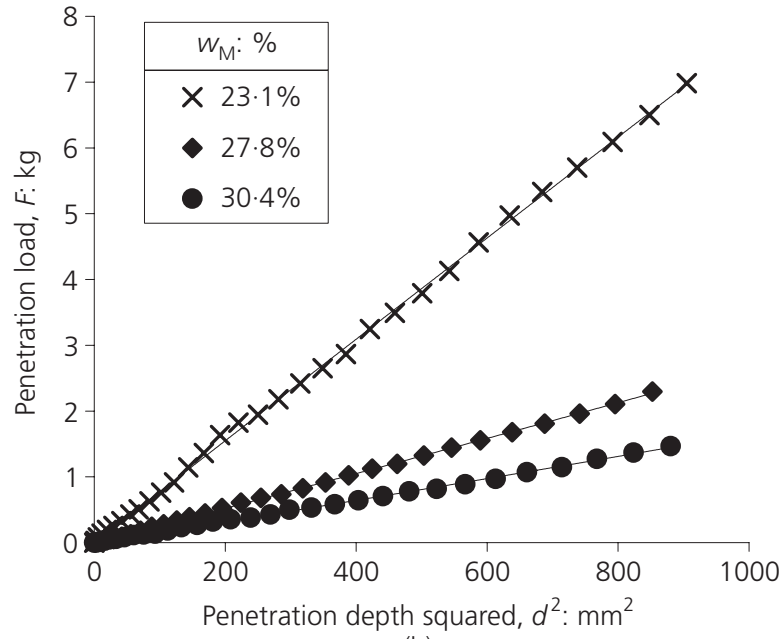

(b)

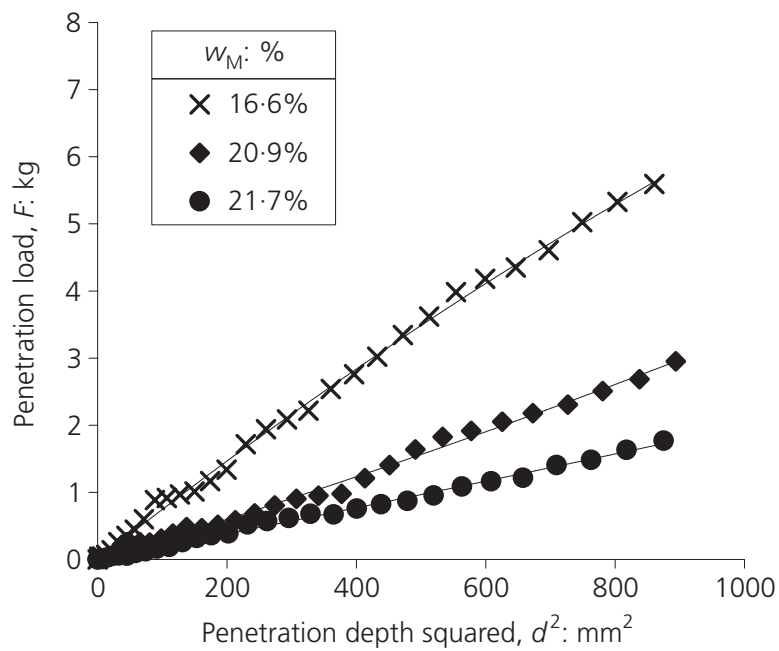

(d)

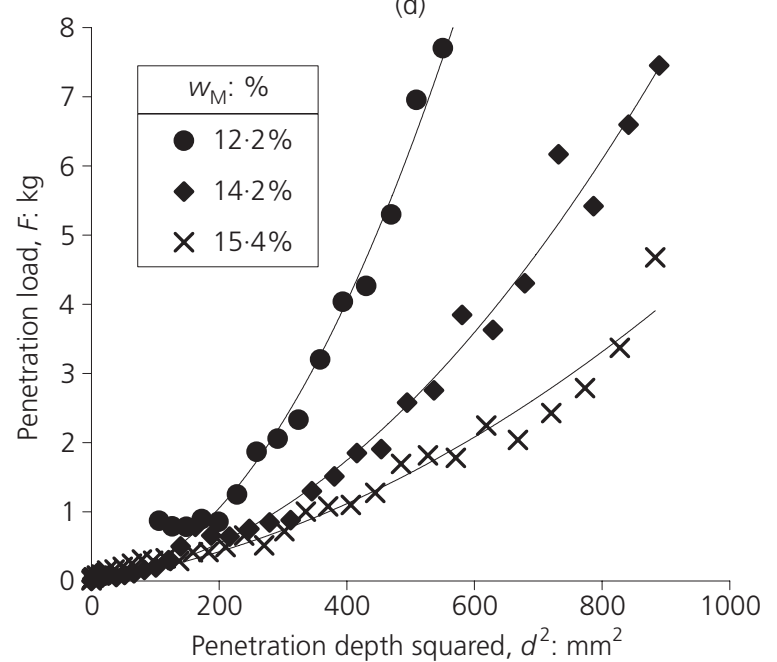

(f) 
For each mixture, a plot of the moisture content against penetration depth associated with an $8 \mathrm{~kg}$ penetration load is constructed, from which the moisture contents associated with the theoretically derived penetration depth of $11.55 \mathrm{~mm}$ are determined: see Figure 5. These moisture contents are by definition the $\mathrm{PL}_{100 \mathrm{M}}$ index.

The corresponding results of the fall-cone tests are shown in Figure 6, from which the liquid limit $\left(\mathrm{LL}_{\mathrm{M}}\right)$ for each mixture is established. The $\mathrm{LL}_{\mathrm{M}}$ values derived from the data shown in Figure 6 can be compared with estimates based on the respective quantities of clay and gravel. Assuming a value of the gravel moisture content of $4 \%$ and a liquid limit of the Reading clay of $57 \%$, estimates of the liquid limit of the mixtures $\left(\mathrm{LL}_{\mathrm{M}}\right)$ can be determined. These are shown in Figure 7 (open squares, designated $\mathrm{LL}_{\mathrm{M}}$ (estimated)) as a linear plot, deviating slightly from the actual measured $\mathrm{LL}_{\mathrm{M}}$ values. This basis of interpretation is used in the British Standard and National House Building Council (NHBC) approaches discussed later in Section 5.2.

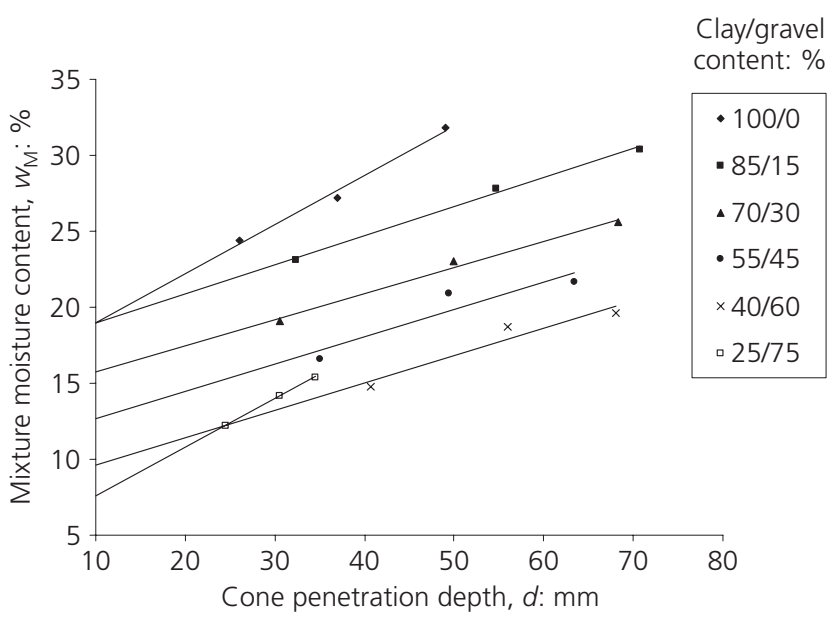

Figure 5. Quasi-static cone penetration results; moisture content against penetration depth at $8 \mathrm{~kg}$ penetration load

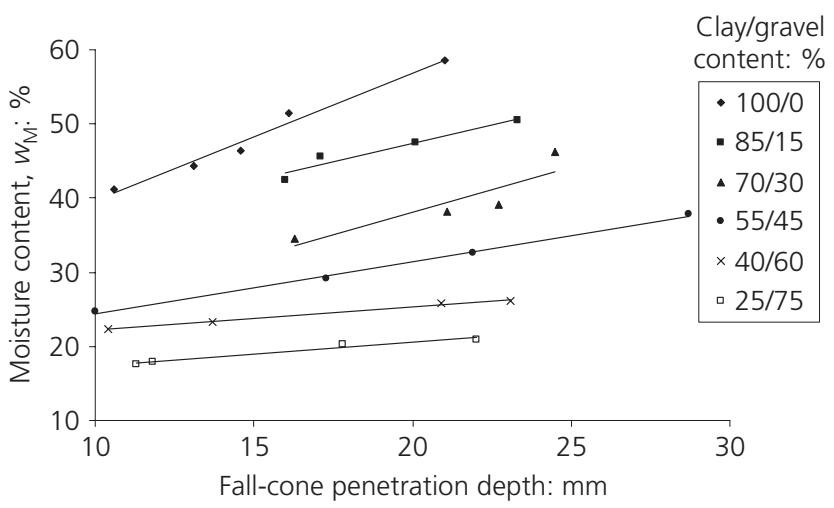

Figure 6. Summary of fall-cone test results

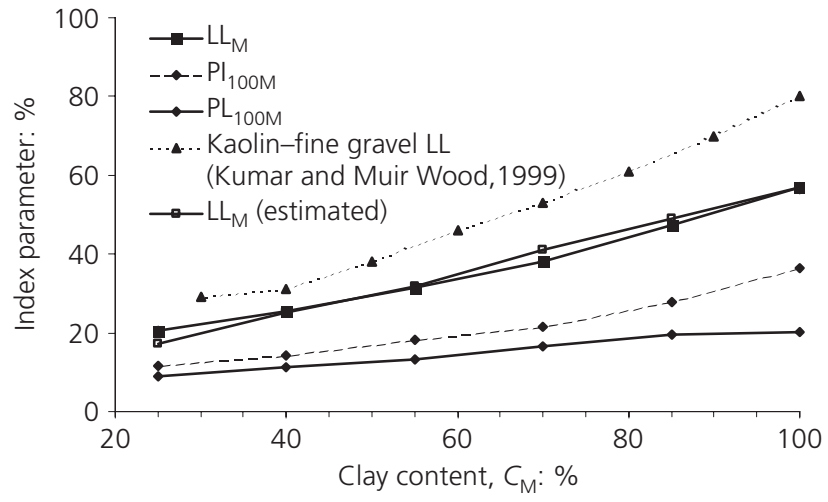

Figure 7. Index limit of mixture ( $\mathrm{LL}_{\mathrm{M}}, \mathrm{PL}_{100 \mathrm{M}}$ and $\left.\mathrm{Pl}_{100 \mathrm{M}}\right)$ as function of clay content

Mixture consistency limits $\left(\mathrm{LL}_{\mathrm{M}}\right.$ and $\mathrm{PL}_{100 \mathrm{M}}$ ) and plasticity indices $\left(\mathrm{PI}_{100 \mathrm{M}}\right)$ are also plotted as a function of the mixture clay content in Figure 7. The effect of the LL and $\mathrm{PL}_{100}$ tests being conducted at different mixture moisture contents is manifested in the steeper and more non-linear slope observed for the higher moisture contents associated with the LL, as compared with the flatter slope observed for the $\mathrm{PL}_{100}$.

The response of the mixtures to cone penetration is further illustrated in Figure 8, showing a plot of the index parameters normalised to the clay content (Equations 7 to 9) against the clay content of the mixture. In both Figures 7 and 8, data reported by Kumar and Muir Wood (1999) for mixtures of kaolin clay and fine gravel are also presented. It is apparent that these data are consistent with the results obtained from this study.

\section{Discussion}

5.1 Effect of coarser fraction on index properties As shown in Figure 8, the influence of the coarse fraction in fallcone and quasi-static penetration tests is similar, and is well

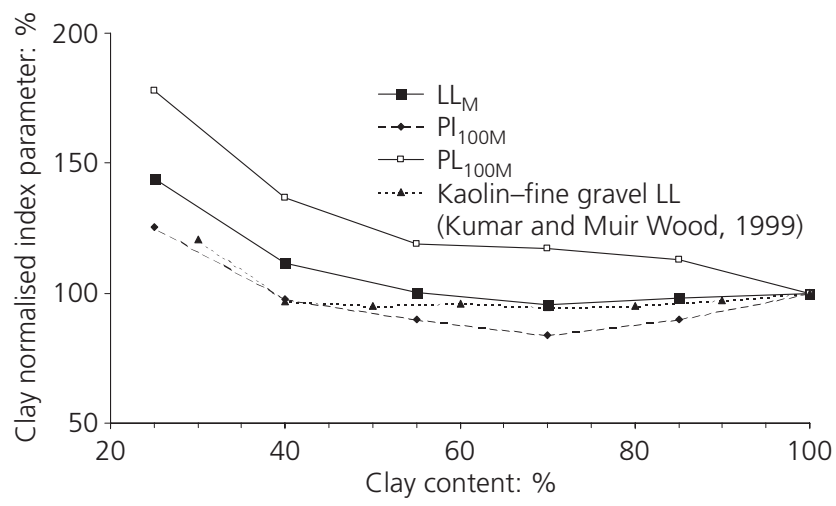

Figure 8. Clay normalised index/limit of mixture as function of clay content 
illustrated through the derived index parameters. It is apparent that the clay phase controls the behaviour of the mixture until the clay content falls below about $55 \%$ ( $45 \%$ gravel), beyond which a significant influence of the gravel on the behaviour of the mixture is observed. This result is in good agreement with studies reported by Lupini et al. (1981) on mixtures of London clay and Happisburgh till (granular volume fraction $0 \cdot 3-0 \cdot 4$ ), both of which also belong to the Lambeth group, as well as data reported for fall-cone tests on kaolin-gravel mixtures (Kumar and Muir Wood, 1999).

The significant influence of high gravel content on the mixture behaviour is assumed to result from the interaction between the gravel particles. The amount of gravel required to generate interaction between gravel particles can be simply estimated by considering the maximum void ratio (loosest packing) of the gravel matrix. First contact between gravel grains in the mixture will occur when the gravel attains its maximum void ratio, the voids all being filled with clay. The gravel used in this study has a maximum void ratio of 0.87 . This corresponds to a granular volume fraction of $0.53(=1 / 1 \cdot 87)$, or by weight a gravel fraction of about $0.50(=0.53 \times 2.65 / 2.79)$.

\subsection{Determination of mixture plasticity}

At present, guidance for the determination of the plasticity of a mixed soil with a fraction coarser than $0.425 \mathrm{~mm}$ is provided by the NHBC standards (NHBC, 2008) and BS 1377-2 (BSI, 1990). The NHBC suggests modifying the PI of the fraction finer than $0.425 \mathrm{~mm}$ by multiplying it by the percentage of soil particles smaller than $0.425 \mathrm{~mm}$ to obtain a plasticity index for the mixture $\left(\mathrm{PI}_{\mathrm{M}}=\mathrm{PI} \times(\%\right.$ soil $\left.<0.425 \mathrm{~mm})\right)$. This adjustment is applicable for soils with a coarse fraction less than $65 \%$ and a modified PI of at least $10 \%$, which may be classified as shrinkable. BS 1377-2 (BSI, 1990) suggests modification of mixture moisture contents assuming a linear correlation between the clay fraction and the consistency limits. Clearly, the disadvantage of both of these approaches is that conventional index tests must be performed, and then adjusted to cater for the presence of the coarser fraction. Consequently, the coarse and fine constituents of the mixture must be separated. The study reported here demonstrates an approach to determining the plasticity of soil mixtures by direct testing of the mixture, without the need to separate the fine and coarse components.

The approach utilises the quasi-static cone penetration test and the associated $\mathrm{PL}_{100}$ index, combined with a conventional fallcone LL test, both tests being performed directly on the soil mixture. From these tests the plasticity, quantified through the plasticity index $\mathrm{PI}_{100}$, of a soil mixture even with a significant fraction coarser than $0.425 \mathrm{~mm}$ can be established.

Figure 9 shows a comparison of the plasticity index obtained through the NHBC approach $\left(\mathrm{PI}_{\mathrm{NHBC}}\right)$ and that obtained from the quasi-static penetration approach, $\mathrm{PI}_{100}$. Although the two approaches yield similar results, it is apparent that a linear relation-

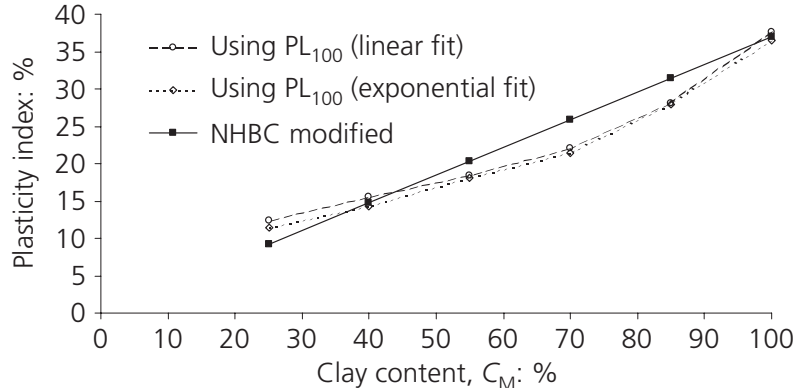

Figure 9. Direct $\mathrm{PL}_{100}$ based $\left(\mathrm{Pl}_{100 \mathrm{M}}\right)$ and $\mathrm{NHBC}$ modified $\left(\mathrm{Pl}_{\mathrm{NHBC}}\right)$ plasticity index of mixture as function of clay content

ship between PI and clay content is valid only for a limited gravel content, a feature that cannot be captured by the NHBC or British Standards approach.

\section{Conclusions}

This paper has presented a method for determining the plasticity of clay-gravel mixtures directly, using a conventional fall-cone apparatus and a quasi-static cone penetration test. Using this approach, the effect of the gravel on the plasticity of the mixtures was evaluated through the use of index parameters (liquid limit, plastic limit and plasticity index), from which the following conclusions can be drawn.

(a) The plasticity of mixtures of highly plastic clays and fine gravel appears to be linearly dependent on the gravel fraction content up to a value about $50 \%$.

(b) The gravel content required to influence the mixture response significantly is associated with the maximum void ratio (loosest packing) of the gravel.

(c) Quasi-static cone penetration tests may be used to determine a plastic limit for mixtures of coarse- and fine-grained soils. This plastic limit can be defined by the $\mathrm{PL}_{100}$ value.

(d) The plasticity, defined through the $\mathrm{PI}_{100}$ index, of a finegrained soil with a significant coarse fraction can be determined without the requirement to remove the coarse fraction, through the use of conventional LL testing and quasi-static penetration tests performed directly on the mixture.

(e) The plasticity of soil mixtures defined through the $\mathrm{PI}_{100}$, and obtained directly from the soil mixture, is in good agreement with other approaches based on modifying the conventional plasticity index, PI, to account for the presence of a coarse fraction.

\section{Acknowledgement}

The authors are grateful to the University of Brighton for funding the development of the soil mini-penetrometer, and supporting the research programme. 


\section{REFERENCES}

Atkinson JH (1993) An Introduction to the Mechanics of Soils and Foundations. McGraw-Hill, London, UK.

Brown PJ and Huxley MA (1996) The cone factor for a $30^{\circ}$ cone. Ground Engineering 29(12): 34-36.

BSI (1990) BS 1377: Part 2: Methods of Test for Soils for Civil Engineering Purposes. BSI, Milton Keynes, UK.

Dumbleton MJ and West G (1966) The Influence of the Coarse Fraction on the Plastic Properties of Clay Soils. Road Research Laboratory, Crowthorne, UK, RRL Report No. 36.

Hansbo S (1957) A new approach to the determination of the shear strength of clay by the fall cone test. Proceedings of the Royal Swedish Geotechnical Institute 14: 7-47.

Houlsby GT (1982) Theoretical analysis of the fall cone test. Géotechnique 32(2): 111-118.

Karlsson R (1961) Suggested improvements in the liquid limit test, with reference to flow properties of remoulded clays. Proceedings of the 5th International Conference on Soil Mechanics and Foundation Engineering, Paris, vol. 1, 171184.

Koumoto T and Houlsby GT (2001) Theory and practice of the fall cone test. Géotechnique 51(8): 701-712.

Kumar GV (1996) Some Aspects of the Mechanical Behaviour of Mixtures of Kaolin and Coarse Sand. PhD thesis, University of Glasgow, UK.

Kumar GV and Muir Wood D (1999) Fall cone and compression tests on clay-gravel mixtures. Géotechnique 49(6): 727-739.

Kyambadde BS (2003) The Effect of Gravel on the Index Properties of Reading Clay. MSc thesis, University of Brighton, UK.

Kyambadde BS (2010) Strength and Consistency Limits from Quasi-Static Cone Tests. PhD thesis, University of Brighton, UK.

Lupini JF, Skinner AE and Vaughan PR (1981) The undrained residual strength of cohesive soils. Géotechnique 31(2): 181213.

Medhat F and Whyte IL (1986) An appraisal of soil index tests. In Site Investigation Practice: Assessing BS 5930 (Hawkins
AB (ed.)). Geological Society, London, UK, Engineering Geology Special Publications, vol. 2, pp. 317-323.

Mitchell JK and Soga K (2005) Fundamentals of Soil Behaviour, 3 rd edn. Wiley, New York, NY, USA.

Muir Wood D and Kumar GV (2000) Experimental observations of behaviour of heterogeneous soils. Mechanics of CohesiveFrictional Materials 5(5): 373-398.

NHBC (2008) Building near trees. NHBC Standards. National Housing Building Council, Amersham, UK, Chapter 4.2.

Sharma B and Bora PK (2003) Plastic limit, liquid limit and undrained shear strength of soil: reappraisal. Journal of Geotechnical and Geoenvironmental Engineering, ASCE 129(8): 774-777.

Sivapullaiah PV and Sridharan A (1985) Liquid limit of soil mixtures. ASTM Geotechnical Testing Journal 8(3): 111-116.

Sivakumar V, Glynn D, Cairns P and Black JA (2009) A new method of measuring plastic limit of fine materials. Géotechnique 59(10): 813-823.

Stone KJL and Kyambadde BS (2005) The determination of undrained shear strength and plasticity properties from quasistatic penetration tests. In Frontiers in Offshore Geotechnics: Proceedings of the International Symposium on Frontiers in Offshore Geotechnics (ISFOG 2005), Perth (Gourvenec S and Cassidy M (eds)). Taylor and Francis, Abingdon, UK, pp. $1095-1100$.

Stone KJL and Kyambadde BS (2007) The determination of strength and index properties of fine-grained soils using a soil mini-penetrometer. Journal of Geotechnical and Geoenvironmental Engineering, ASCE 133(6): 667-673.

Stone KJL and Phan KD (1995) Cone penetration tests near the plastic limit. Géotechnique 45(1): 155-158.

Wood DM (1985) Some fall-cone tests. Géotechnique 35(1): 64-68.

Wood DM and Wroth CP (1978) The use of the cone penetrometer to determine the plastic limit of soils. Ground Engineering 11(3): 37.

Wroth CP and Wood DM (1978) The correlation of index properties with some basic engineering properties of soils. Canadian Geotechnical Journal 15(2): 137-145.

\section{WHAT DO YOU THINK?}

To discuss this paper, please email up to 500 words to the editor at journals@ice.org.uk. Your contribution will be forwarded to the author(s) for a reply and, if considered appropriate by the editorial panel, will be published as a discussion in a future issue of the journal.

Proceedings journals rely entirely on contributions sent in by civil engineering professionals, academics and students. Papers should be $2000-5000$ words long (briefing papers should be 1000-2000 words long), with adequate illustrations and references. You can submit your paper online via www.icevirtuallibrary.com/content/journals, where you will also find detailed author guidelines. 